Mens

revue d'histoire intellectuelle de l'Amérique française

Mourad Djebabla-Brun. Se souvenir de la Grande Guerre : la mémoire plurielle de 14-18 au Québec. Montréal, VLB éditeur, 2004. 181 p.

\title{
Desmond Morton
}

Volume 6, numéro 1, automne 2005

URI : https://id.erudit.org/iderudit/1024260ar

DOI : https://doi.org/10.7202/1024260ar

Aller au sommaire du numéro

Éditeur(s)

Centre de recherche en civilisation canadienne-française

ISSN

1492-8647 (imprimé)

1927-9299 (numérique)

Découvrir la revue

Citer ce compte rendu

Morton, D. (2005). Compte rendu de [Mourad Djebabla-Brun. Se souvenir de la Grande Guerre : la mémoire plurielle de 14-18 au Québec. Montréal, VLB éditeur, 2004. 181 p.] Mens, 6(1), 115-118. https://doi.org/10.7202/1024260ar d'utilisation que vous pouvez consulter en ligne.

https://apropos.erudit.org/fr/usagers/politique-dutilisation/ 


\section{Mourad Djebabla-Brun. Se souvenir de la Grande Guerre : la mémoire plurielle de 14-18 au Québec. Montréal, VLB éditeur, 2004. 181 p.}

La Première Guerre mondiale s'est terminée avec l'Armistice du 11 novembre 1918. La reine Mary d'Angleterre a rapidement qualifié ce moment de « plus grand jour dans l'histoire du monde » et plusieurs pensaient évidemment de même. Son époux, le roi George V, sans doute de l'avis et du consentement aussi bien de ses ministres que de sa femme, enjoignit sagement ses loyaux sujets autour du monde à considérer le 11 novembre comme un jour du Souvenir commémorant non seulement la victoire des Alliés sur l'Empire allemand, mais aussi les énormes sacrifices qui l'avaient rendue possible.

Au Québec, bien sûr, le sentiment de loyauté des sujets du roi George n'était pas à son plus fort. Mis à part les débordements initaux animés d'un esprit patriotique, quoique mitigés par la crainte de voir les Britanniques se soustraire d'une - quelconque façon à leurs obligations envers leurs nouveaux alliés français, la participation à la Grande Guerre n'y a reçu qu'un appui limité. Comme Henri Bourassa l'avait enseigné à sa génération, la Grande-Bretagne devait protéger le Canada, et non l'inverse. Quant à la France, n'avait-elle pas abandonné la Nouvelle-France en 1763, puis aggravé cette offense par un récent sursaut d'anticléricalisme républicain? Et quel devoir quiconque avait-il envers le tsar de Russie ? Sans compter que les Canadiens français qui s'engagaient dans le Corps expéditionnaire canadien y rencontraient incompréhension et abus, aggravés par l'unilinguisme obtus du reste du Canada entre 1914 et 1918. Pire encore, lorsque l'incompétence et la corruption du gouvernment tarirent même la source de volontaires pro-britanniques au Canada anglais, la majorité obligea la minorité à aller à la guerre en imposant la conscription. Selon toute apparence, la plupart des Québécois ont accueilli 
le "plus grand jour» de la reine Mary avec une indifférence maussade, comme il convient à des victimes d'oppression. Pour une société qui avait fondé son identité nationale en résistant à la conscription, les héros de 1918 n'étaient pas ces hommes bercés d'illusions qui s'étaient battus et étaient morts pour la cause étrangère de l'Empire britannique, mais ceux qui avaient résisté à la conscription, parfois même au prix d'une peine de prison.

Ce n'était toutefois pas le but de Mourad Djebabla-Brun de déterminer qui a eu raison ou qui a eu tort lors de la Grande Guerre ni de revisiter les débats acrimonieux au sujet de la conscription de 1917-1918, mais plutôt de rappeler comment la guerre a été commémorée au Québec par le biais de monuments, de cérémonies, de programmes et de manuels scolaires, de romans et par tous les autres éléments qui façonnent la mémoire sociale. Ce livre, issu d'un mémoire de maitrise présenté à l'UQAM, constitue un excellent compagnon à l'ouvrage de Béatrice Richard, intitulé La mémoire de Dieppe. Radioscopie d'un mythe (VLB éditeur, 2002), qui met en lumière la complexité similaire et le même présentisme de la mémoire québécoise concernant le raid de Dieppe de 1942.

Les historiens canadiens-anglais en sont venus à accepter l'idée que le Canada a trouvé son identité nationale lors de la Première Guerre mondiale. Si les nations sont créées, comme le disait Ernest Renan, " en faisant de grandes choses ensemble», avoir survécu à l'attaque au gaz allemand à Ypres en avril 1915 ou avoir capturé la crête de Vimy deux ans plus tard apparaissaient évidemment comme de "grandes choses" aux Canadiens. Même si la participation canadienne-française pouvait sembler quelque peu limitée, une compagnie francophone du $14^{\mathrm{e}}$ bataillon ainsi que le $22^{\mathrm{e}}$ bataillon canadienfrançais comptaient parmi les Canadiens présents. Lorsque le Canada a trouvé le courage de signer le Traité de Versailles, d'occuper son propre siège à la Société des Nations et de mettre 
fin aux derniers vestiges de l'autorité impériale en 1931, estce que ces accomplissements ont réalisé les rêves de Henri Bourassa ou les fantaisies de Sir Sam Hughes?

Comme nous le rappelle Djebabla-Brun, peu, si ce n'est aucune, de ces considérations en sont venues à faire partie de la mémoire dominante au Québec. Les monuments commémoratifs de la guerre sont apparus dans les années 1920 et 1930 , non parfois sans controverse concernant l'emplacement approprié pour tenir les activités commémoratives locales lors du jour du Souvenir. Le dévoilement de ces monuments était accompagné, nous dit-on, de discours qui cherchaient à lier les soldats de la guerre de 1914-1918 à Adam Dollard des Ormeaux, à Madeleine de Verchères et à d'autres héros de la Nouvelle-France. Le contenu des manuels scolaires a évolué avec le désillusionnement universel d'après 1918 par rapport à la guerre. Bien que les soldats du Québec aient servi dans plusieurs unités canadiennes, les références à leur participation au combat étaient généralement limitées au $22^{\mathrm{e}}$ bataillon provenant du Québec. Dans la version de Guy LaViolette du texte "Mon Pays", un soldat canadien-français est dépeint comme portant le casque et le manteau caractéristiques du poilu de l'armée française, et non comme les «tommies» canadiens-anglais parés d'un uniforme kaki et d'un casque en forme de bassin. L'auteur a peut-être fait cette erreur en s'inspirant des affiches de recrutement tout aussi erronées dessinées par Olivar Asselin pour son $163^{\mathrm{e}}$ bataillon, les « Poilsaux-pattes ». Alors que les auteurs ne s'entendent pas sur son importance, le conservatisme clérical prudent des Frères des Écoles chrétiennes (FEC) était partout évident. Ainsi, parmi les horreurs de la guerre, Hermann Plante mentionne, dans sa version de "Mon Pays ", "un phénomène nouveau et antisocial : le travail des femmes à l'usine ».

Selon Djebabla-Brun, des mémoires rivales concernant la Grande Guerre ont été articulées au Canada français tout 
au long du $\mathrm{XX}^{\mathrm{e}}$ siècle, tout comme des projets rivaux concernant l'avenir du Québec, toujours accompagnées de silence et, en alternance, d'ignorance et d'indifférence parmi tous ceux qui ignorent les vieilles et ennuyeuses aspirations du passé et les mémoires auxquelles elles ont donné forme. Lorsque les idées vieillissent, nonobstant l'aspect passionné et spectaculaire qu'elles avaient à leur naissance, elles finissent par ennuyer, par être oubliées, par évoluer. Étant donné que les derniers vétérans de la Première Guerre mondiale sont maintenant centenaires, il est clair que d'autres événements ont contesté, les uns après les autres, la prétention de la reine Mary quant à la signification unique du 11 novembre.

Dans Se souvenir de la Grande Guerre, Mourad DjebablaBrun et le directeur de la collection, Robert Comeau, professeur titulaire de la Chaire Hector-Fabre en histoire à l'UQAM, ont contribué substantiellement à notre connaissance de nousmêmes et du façonnement de notre mémoire collective. Ils nous ont éloquemment et heureusement rappelé qu'au Québec, comme ailleurs probablement, l'histoire "officielle » ou " autorisée », que ce soit dans les écoles, dans les parcs ou à la télévision, est un artéfact modelé pour servir des objectifs politiques. Cette histoire n'est ni meilleure, ni pire, ni plus intelligente, ni plus insensée que ces derniers. Comme le professeur Peter Seixas l'a soutenu, nous devons « comprendre l'histoire " au lieu de la mémoriser. Mourad Djebabla-Brun nous a donné quelques outils fort valables pour y arriver.

Desmond Morton Département d'bistoire Université McGill 